\title{
Trends in the Prevalence and Awareness of High Cholesterol among Adults in Mississippi, United States
}

\author{
Rasaki Aranmolate ${ }^{1 *}$, Olubunmi S. Obayemi ${ }^{2}$ \\ 1 Jackson State University School of Public Health, MS 39213 Jackson, USA \\ ${ }^{2}$ Liberty University, Department of Public and Community Health Promotion, Lynchburg VA, 24515, USA
}

*Corresponding Author: J00787960@students.jsums.edu

Citation: Aranmolate, R. and Obayemi, O. S. (2018). Trends in the Prevalence and Awareness of High Cholesterol among Adults in Mississippi, United States. European Journal of Environment and Public Health, 2(2), 06. https:// doi.org/10.20897/ejeph/92010

Published: September 28, 2018

\begin{abstract}
Elevated level of blood cholesterol (total cholesterol $>240 \mathrm{mg} / \mathrm{dL}$ ) is one of the major risk factor for heart disease, which is the leading cause of death in the United States. This challenge makes public health organizations and their partners to design programs that will reduce the prevalence of high cholesterol by increasing public awareness and screening. The purpose of this study was to determine trends in the prevalence and awareness of high cholesterol among adults in Mississippi. Behavioral Risk Factor Surveillance System(BRFSS) of 2015, a cross-sectional, stratified, multistage probability sample survey of the Mississippi residents, noninstitutionalized population examined the prevalence and trend of high cholesterol according to sex and ethnicity for 5039 ( $n=1703$ male and $n=3336$ females) adults aged 18 to 65 and above. The trends in the percentage of adults screened for elevated level of cholesterol and its awareness was examined using t-test statistical and frequency distribution to determine the percentage differences in the groups. About 38.6\% male and 38.3\% females had high cholesterol when screened. In addition, $41.9 \%$ of non-Hispanic whites was aware of high cholesterol which is higher when compared to $34.2 \%$ nonHispanic blacks. These findings indicated an increased level of awareness of high cholesterol among nonHispanic whites than non-Hispanic blacks. More attention should be focused on cholesterol screening and awareness, specifically among non-Hispanic blacks in Mississippi.
\end{abstract}

Keywords: screening, cholesterol, awareness, Mississippi

Abbreviations: HBC: High Blood Cholesterol; LDL: low density lipoprotein cholesterol; BRFSS; Behavioral Risk Factor Surveillance System; CHD: Coronary Heart Disease; NCEP: National Cholesterol Education Program Adult Treatment Panel

\section{INTRODUCTION}

One of the important leading cause of mortality in the United States is heart disease. Hypercholesterolemia is recognized as a major risk factor for cardiovascular disease (American Heart Association, 2005). Due to this important health condition, public health agencies and their allies have sought for a decrease in the prevalence of total blood cholesterol through increase awareness of high blood cholesterol (HBC) screening, and actions towards reducing high blood cholesterol (American Heart Association, 2005).

The level of blood cholesterol is an important health indicator and since the total cholesterol blood level of 240 $\mathrm{mg} / \mathrm{dl}$ or higher constitute a potential risk factor for a cardiovascular problem (American Heart Association, 2005). 
It is important for individuals aged 20 years and above to have a lipid profile check including total cholesterol, low density lipoprotein cholesterol (LDL), high density lipoprotein cholesterol (HDL), and Triglycerides once in every five years (American Heart Association, 2005). There are two types of cholesterol, High Density Lipoprotein cholesterol (HDL) and Low Density Lipoprotein cholesterol (LDL) (American Heart Association, 2005).

LDL level of $<100 \mathrm{mg} / \mathrm{dl}$ (Normal range 130-159 mg/dl) are more likely to cause atherogenesis (American Heart Association, 2005), moreover, LDL level of $160 \mathrm{mg} / \mathrm{dl}$ or higher increases the risk for heart disease (American Heart Association, 2005). The amount of total cholesterol should not exceed $200 \mathrm{mg} / \mathrm{dl}$, the borderline increase of total cholesterol is $200-239 \mathrm{mg} / \mathrm{dl}$, and total cholesterol of more than $240 \mathrm{mg} / \mathrm{dl}$ is high (American Heart Association, 2005).

Approximately one in three American adults has high cholesterol (Benjamin et al., 2017). About 71 million American Adults (33.5\%) have high low density Lipoprotein (LDL), or "bad cholesterol" (CDC, 2011). 1 out of every 3 adults with high LDL cholesterol managed it successfully (CDC, 2011). The leading cause of mortality in Mississippi is heart disease and stroke, which is responsible for more than one third of all mortalities (Mississippi Behavioral Risk Factor Surveillance System, 2008). In Mississippi, the percentages of adults who had cholesterol screening in 5 years prior to 2012 was not statistically significant based on race, gender, and education or poverty level (Vanessa, 2014), However, when compared to healthy people 2020 target of $82.1 \%$, about $70 \%$ of Americans adults living in Mississippi had their blood cholesterol screening in the last 5 years (Vanessa, 2014).

About, 78 million U.S adults (approximately 37\%) in 2011 and 2012 had significantly low LDL (Mercado et al., 2017). A total of 95 million American adults aged 20 years or older had total cholesterol greater than $200 \mathrm{mg} / \mathrm{dl}$ (Benjamin et al., 2017). Furthermore, about 29 million American adults had total cholesterol greater than 240 $\mathrm{mg} / \mathrm{dl}$ (Benjamin et al., 2017). Increased total cholesterol were found in approximately $7 \%$ of American children and adolescents between ages 6 and 19 years old (Nguyen et al., 2015).

In addition, between 1999 and 2002, the percentages of blacks and Mexican Americans who had been screened for high blood cholesterol over the past 5 years was lowered when compared to whites (Ford et al., 2003). The percentages of blacks and Mexican Americans with high blood cholesterol (HBC) who were informed of their cholesterol level by medical practitioners was lower than whites (Ford et al., 2003). Furthermore, women were more likely to check their blood cholesterol than men (Ford et al., 2003).

According to healthy 2020, the leading cause of death in the United States is cardiovascular disease, while stroke is the 5th leading cause of mortality in the United States (Murphy et al., 2015). Cardiovascular disease and stroke are known to be among the most common and expensive health conditions in the US, which nearly accounted for $\$ 320$ billion in health care spending and associated costs every year (Mozaffarian et al., 2016). The common risk factors for cardiovascular disease are high cholesterol, high blood pressure, cigarette smoking, diabetes, unhealthy diet, physical inactivity, overweight and obesity (Mozaffarian et al., 2016). However, HBC, high blood pressure, cigarette smoking are the major risk factors responsible for the cardiovascular diseases (Yoon et al., 2015). It is important to know that the increasing prevalence of abnormal cholesterol in children and adolescents (Aranmolate, 2017a) can be associated with obesity, which can lead to cardiovascular disease during adulthood (Aranmolate, 2017b). Although, significant changes have been made across American population in the area of diet, physical activity, control of high blood pressure and cholesterol, smoking cessation, and appropriate aspirin use (Ritchey et al., 2014).

There are substantial disparities in gender, age, race/ethnicity, geographic and socio-economic status (Havranek et al., 2015). Despite the decline over time, disparities in HBC level continue to rise (Mensah et al., 2005). Studies have shown that the differences in prevention and treatment of cholesterol may be associated with the persistence of disparities in cholesterol screening (Link and Phelan, 1995). American adults who has a total cholesterol of more $240 \mathrm{mg} / \mathrm{dl}$ is considered high, hence requiring medical treatment (American Heart Association, 2006). Behavioral Risk Factor Surveillance system (BRFSS) data indicated that cholesterol screening has increased from $67.6 \%$ to $73.1 \%$ between 1991 and 2003 (CDC, 2005a).

Moreover, cholesterol awareness reduced by $1 \%$ between 1988 and 1994 while the average total cholesterol reduced by 3\% between 1999-2002 (Arnett et al., 2005). National Cholesterol Education Panel (NCEP) recommended life style modification to reduce LDL, but adults at increased risk will require treatment with medication to control their high cholesterol (National Cholesterol Education Program, 2001). A study suggested that total adherence to the National Cholesterol Education Program Adult Treatment Panel 111 (NCEP ATP 111) primary prevention guidelines in individuals between 35-85 years could prevent 20,000 myocardial infarctions and 10,000 mortalities from Coronary Heart Disease (CHD) and save $\$ 2.8$ billion in CHD associated health care expenditure per year (Pletcher et al., 2009).

Several studies have been conducted on trends in the prevalence (Aranmolate, 2017a) and awareness of high cholesterol in the United States, but no studies have been done on the trends in the prevalence and awareness of high cholesterol among adults in Mississippi. The aim of this study was to examine the trends in the prevalence and awareness of high cholesterol among adults in Mississippi, United States. 
Table 1. Adults who have had their blood cholesterol checked and have been told it was high in Mississippi 2015

\begin{tabular}{|c|c|c|c|c|c|c|}
\hline \multirow{2}{*}{ VARIABLES } & \multicolumn{3}{|c|}{ YES } & \multicolumn{3}{|c|}{ NO } \\
\hline & Percent (\%) & $95 \% \mathrm{CI}$ & $\mathbf{N}$ & Percent (\%) & $95 \% \mathrm{CI}$ & $\mathbf{N}$ \\
\hline \multicolumn{7}{|l|}{ Gender } \\
\hline Male & 38.6 & $35.6-41.6$ & 813 & 64.4 & $58.4-64.4$ & 947 \\
\hline Female & 38.9 & $36.6-41.2$ & 1600 & 61.1 & $58.8-63.5$ & 1839 \\
\hline \multicolumn{7}{|l|}{ Age Group } \\
\hline $18-24$ & $\mathrm{~N} / \mathrm{A}$ & $\mathrm{N} / \mathrm{A}$ & $\mathrm{N} / \mathrm{A}$ & 92.9 & $87.8-98.0$ & 88 \\
\hline $25-34$ & 12.9 & $8.5-17.2$ & 41 & 87.1 & $82.8-91.5$ & 266 \\
\hline $35-44$ & 27.7 & $22.9-32.5$ & 135 & 72.3 & $67.5-77.1$ & 358 \\
\hline$\overline{45-54}$ & 38.4 & $34.1-42.8$ & 298 & 61.6 & $57.2-66.0$ & 476 \\
\hline $55-64$ & 54.6 & $50.9-58.3$ & 659 & 45.4 & $41.7-49.1$ & 617 \\
\hline $65+$ & 57.6 & $54.8-60.3$ & 1271 & 42.4 & $39.7-45.2$ & 981 \\
\hline \multicolumn{7}{|l|}{ Race } \\
\hline White, non-Hispanic & 41.9 & $39.6-44.2$ & 1605 & 58.1 & $55.8-60.5$ & 1720 \\
\hline Black, non-Hispanic & 34.2 & $31.0-37.4$ & 769 & 65.8 & $62.9-69.0$ & 1009 \\
\hline AI/AN, non-Hispanic & $\mathrm{N} / \mathrm{A}$ & $\mathrm{N} / \mathrm{A}$ & $\mathrm{N} / \mathrm{A}$ & $\mathrm{N} / \mathrm{A}$ & $\mathrm{N} / \mathrm{A}$ & $\mathrm{N} / \mathrm{A}$ \\
\hline Asian, non-Hispanic & $\mathrm{N} / \mathrm{A}$ & $\mathrm{N} / \mathrm{A}$ & $\mathrm{N} / \mathrm{A}$ & $\mathrm{N} / \mathrm{A}$ & $\mathrm{N} / \mathrm{A}$ & $\mathrm{N} / \mathrm{A}$ \\
\hline Native Hawaiian, non-Hispanic & $\mathrm{N} / \mathrm{A}$ & $\mathrm{N} / \mathrm{A}$ & $\mathrm{N} / \mathrm{A}$ & $\mathrm{N} / \mathrm{A}$ & $\mathrm{N} / \mathrm{A}$ & $\mathrm{N} / \mathrm{A}$ \\
\hline Other, non-Hispanic & $\mathrm{N} / \mathrm{A}$ & $\mathrm{N} / \mathrm{A}$ & $\mathrm{N} / \mathrm{A}$ & $\mathrm{N} / \mathrm{A}$ & $\mathrm{N} / \mathrm{A}$ & $\mathrm{N} / \mathrm{A}$ \\
\hline Multiracial, non-Hispanic & $\mathrm{N} / \mathrm{A}$ & $\mathrm{N} / \mathrm{A}$ & $\mathrm{N} / \mathrm{A}$ & $\mathrm{N} / \mathrm{A}$ & $\mathrm{N} / \mathrm{A}$ & $\mathrm{N} / \mathrm{A}$ \\
\hline Hispanic & $\mathrm{N} / \mathrm{A}$ & $\mathrm{N} / \mathrm{A}$ & $\mathrm{N} / \mathrm{A}$ & $\mathrm{N} / \mathrm{A}$ & $\mathrm{N} / \mathrm{A}$ & $\mathrm{N} / \mathrm{A}$ \\
\hline \multicolumn{7}{|l|}{ Level of Education } \\
\hline Less than H.S & 52.2 & $46.7-57.8$ & 374 & 47.8 & $42.3-53.4$ & 289 \\
\hline H.S or G.E.D & 42.0 & $38.7-45.4$ & 811 & 58.0 & $54.6-61.4$ & 782 \\
\hline Some post-H.S & 33.4 & $30.1-36.6$ & 617 & 66.6 & 63.4-69.9 & 779 \\
\hline College Graduate & 32.5 & $29.3-35.6$ & 603 & 67.6 & $64.4-70.7$ & 926 \\
\hline Total & 38.7 & $36.9-40.6$ & 2413 & 61.3 & $59.4-63.1$ & 2786 \\
\hline
\end{tabular}

Data Source: Behavioral Risk Factor Surveillance System, 2015

\section{METHODS}

The data were obtained from Behavioral Risk Factor Surveillance System (BRFSS) in 2015, it samples the US civilian population that are noninstitutionalized in 18 years and above. Participants responded to the questions whether they had ever had a blood cholesterol screening (CDC, 2001). Participants, who reported having ever been screened were questioned if they had ever been told by a health-care expert that they had high blood cholesterol (CDC, 2001). Data were examined according to age group (18-24, 25-34, 35-44, 45-54, 55-64, and $\geq 65$ years), sex, race/ethnicity (white, black, Hispanic, Asian/Pacific Islander, and American Indian/Alaskan Native), and level of education (less than high school diploma, high school diploma or General educational development (G.E.D), some post-high school and college degree) (Klein and Schoenborn, 2001). The percentages of participants who reported being screened for cholesterol in the last 5 years was determined. The trends in the percentage of adults screened for high cholesterol and its awareness was examined using the t-test and frequency distribution to examine the percentage difference in the groups.

\section{RESULTS}

In 2015, the analysis revealed the percentage of persons screened in the last 5 years in Mississippi and were told they had HBC based on gender was 38.6\% (CI = 35.6-41.6) in male and 38.9\% (CI=36.6-41.2) in female while participants who reported no screening was higher among male $(64.4 \%$; $\mathrm{CI}=58.4-64.4)$ when compared to female (61.1\%; CI=58.8-63.5) (Table 1). In addition, the percentage of individuals who reported HBC when screened in the last five years from 65 years and above $(57.6 \%, \mathrm{CI}=54.8-60.3)$ followed by $55-64$ years $(54.6 \%$; $\mathrm{CI}=50.9-58.3)$, 45-54 years (38.4\%; $\mathrm{CI}=34.1-42.8), 35-44(27.7 \%$; $\mathrm{CI}=22.9-32.5)$, and $25-34$ years $(12.9 \%, \mathrm{CI}=8.5-17.2)($ Table 1). The percentage of participants who reported no screening within the last 5 years was highest among aged 1824 years $(92.9 \%$; $C I=87.8-98.0), 25-34$ years $(87.1 \%$; $C I=82.9-91.5), 35-44(72.3 \%$; $\mathrm{CI}=67.5-77.1), 44-54$ (61.6\%; $\mathrm{CI}=57.2-66.0), 55-64(45.4 \%$; $\mathrm{CI}=41.7-49.1)$, lowest percentage was observed among adults aged 65 and above (42.4\%; CI =39.7-45.2) (Table 1). These results revealed increased prevalence of cholesterol screening among the elderly and middle age adult when compared to young adults in Mississippi.

Furthermore, screening prevalence based on race/ethnicity revealed that the prevalence of cholesterol screening for $\mathrm{HBC}$ was higher among non-Hispanic white $(41.9 \%$; $\mathrm{CI}=39.6-44.2)$ when compared to non- 
Table 2. Adults who have had their blood cholesterol checked within the last 5 years in Mississippi 2015

\begin{tabular}{|c|c|c|c|c|c|c|c|c|c|}
\hline \multirow{2}{*}{ VARIABLES } & \multicolumn{3}{|c|}{ Checked in the past 5 years } & \multicolumn{3}{|c|}{ Not Checked in Past 5 years } & \multicolumn{3}{|c|}{ Never Checked } \\
\hline & Percent (\%) & $95 \% \mathrm{CI}$ & $\mathbf{N}$ & Percent (\%) & $95 \% \mathrm{CI}$ & $\mathbf{N}$ & Percent (\%) & $95 \% \mathrm{CI}$ & $\mathbf{N}$ \\
\hline \multicolumn{10}{|l|}{ Gender } \\
\hline Male & 72.8 & $69.8-75.7$ & 1703 & 2.5 & $1.6-3.4$ & 46 & 24.8 & $21.8-27.7$ & 295 \\
\hline Female & 79.0 & $76.8-81.3$ & 3336 & 1.9 & $1.3-2.6$ & 65 & 19.0 & $16.8-21.2$ & 383 \\
\hline \multicolumn{10}{|l|}{ Age Group } \\
\hline $18-24$ & 40.2 & $32.8-47.6$ & 89 & $\mathrm{~N} / \mathrm{A}$ & $\mathrm{N} / \mathrm{A}$ & $\mathrm{N} / \mathrm{A}$ & 57.3 & $50.1-65.0$ & 123 \\
\hline $25-34$ & 59.2 & $53.9-64.6$ & 287 & $\mathrm{~N} / \mathrm{A}$ & $\mathrm{N} / \mathrm{A}$ & $\mathrm{N} / \mathrm{A}$ & 38.3 & $33.0-43.6$ & 167 \\
\hline$\overline{35-44}$ & 77.2 & $72.9-81.5$ & 467 & 3.2 & $1.4-5.1$ & 16 & 19.6 & $15.5-23.6$ & 106 \\
\hline $45-54$ & 82.9 & $79.6-86.2$ & 739 & 2.7 & $1.4-4.0$ & 27 & 14.4 & $11.3-17.5$ & 102 \\
\hline $55-64$ & 91.0 & $88.8-93.1$ & 1243 & 1.3 & $0.6-1.9$ & 22 & 7.8 & $5.8-9.8$ & 91 \\
\hline $65+$ & 94.2 & $92.7-95.8$ & 2205 & 1.3 & $0.7-2.0$ & 26 & 4.4 & $3.1-5.8$ & 89 \\
\hline \multicolumn{10}{|l|}{ Race } \\
\hline White, non-Hispanic & 79.1 & $79.6-81.4$ & 3203 & 3 & $2.1-3.8$ & 91 & 17.9 & $15.7-20.1$ & 354 \\
\hline Black, non-Hispanic & 72.7 & 69.4-75.9 & 1744 & $\mathrm{~N} / \mathrm{A}$ & $\mathrm{N} / \mathrm{A}$ & $\mathrm{N} / \mathrm{A}$ & 26.3 & $23.1-29.5$ & 293 \\
\hline AI/AN, non-Hispanic & $\mathrm{N} / \mathrm{A}$ & $\mathrm{N} / \mathrm{A}$ & $\mathrm{N} / \mathrm{A}$ & $\mathrm{N} / \mathrm{A}$ & $\mathrm{N} / \mathrm{A}$ & $\mathrm{N} / \mathrm{A}$ & $\mathrm{N} / \mathrm{A}$ & $\mathrm{N} / \mathrm{A}$ & $\mathrm{N} / \mathrm{A}$ \\
\hline Asian, non-Hispanic & $\mathrm{N} / \mathrm{A}$ & $\mathrm{N} / \mathrm{A}$ & $\mathrm{N} / \mathrm{A}$ & $\mathrm{N} / \mathrm{A}$ & $\mathrm{N} / \mathrm{A}$ & $\mathrm{N} / \mathrm{A}$ & $\mathrm{N} / \mathrm{A}$ & $\mathrm{N} / \mathrm{A}$ & $\mathrm{N} / \mathrm{A}$ \\
\hline Native Hawaiian, non-Hispanic & $\mathrm{N} / \mathrm{A}$ & $\mathrm{N} / \mathrm{A}$ & $\mathrm{N} / \mathrm{A}$ & $\mathrm{N} / \mathrm{A}$ & $\mathrm{N} / \mathrm{A}$ & $\mathrm{N} / \mathrm{A}$ & $\mathrm{N} / \mathrm{A}$ & $\mathrm{N} / \mathrm{A}$ & $\mathrm{N} / \mathrm{A}$ \\
\hline Other, non-Hispanic & $\mathrm{N} / \mathrm{A}$ & $\mathrm{N} / \mathrm{A}$ & $\mathrm{N} / \mathrm{A}$ & $\mathrm{N} / \mathrm{A}$ & $\mathrm{N} / \mathrm{A}$ & $\mathrm{N} / \mathrm{A}$ & $\mathrm{N} / \mathrm{A}$ & $\mathrm{N} / \mathrm{A}$ & $\mathrm{N} / \mathrm{A}$ \\
\hline Multiracial, non-Hispanic & $\mathrm{N} / \mathrm{A}$ & $\mathrm{N} / \mathrm{A}$ & $\mathrm{N} / \mathrm{A}$ & $\mathrm{N} / \mathrm{A}$ & $\mathrm{N} / \mathrm{A}$ & $\mathrm{N} / \mathrm{A}$ & $\mathrm{N} / \mathrm{A}$ & $\mathrm{N} / \mathrm{A}$ & $\mathrm{N} / \mathrm{A}$ \\
\hline Hispanic & $\mathrm{N} / \mathrm{A}$ & $\mathrm{N} / \mathrm{A}$ & $\mathrm{N} / \mathrm{A}$ & $\mathrm{N} / \mathrm{A}$ & $\mathrm{N} / \mathrm{A}$ & $\mathrm{N} / \mathrm{A}$ & $\mathrm{N} / \mathrm{A}$ & $\mathrm{N} / \mathrm{A}$ & $\mathrm{N} / \mathrm{A}$ \\
\hline \multicolumn{10}{|l|}{ Level of Education } \\
\hline Less than H.S & 69.1 & 63.7-74.5 & 642 & $\mathrm{~N} / \mathrm{A}$ & $\mathrm{N} / \mathrm{A}$ & $\mathrm{N} / \mathrm{A}$ & 29.2 & $23.8-34.6$ & 113 \\
\hline H.S or G.E.D & 73.2 & $70.0-76.5$ & 1540 & 2.0 & $1.1-2.9$ & 36 & 24.8 & $21.5-28.0$ & 257 \\
\hline Some post-H.S & 76.1 & $72.8-79.4$ & 1352 & 2.7 & $1.6-3.8$ & 34 & 21.2 & $18.0-24.4$ & 186 \\
\hline College Graduate & 86.9 & $84.4-89.4$ & 1489 & 2.1 & $1.2-3.0$ & 33 & 11.0 & $8.7-13.4$ & 119 \\
\hline Total & 76.0 & $74.2-77.9$ & 5039 & 2.2 & $1.6-2.7$ & 111 & 21.8 & $20.0-23.6$ & 678 \\
\hline
\end{tabular}

Data Source: Behavioral Risk Factor Surveillance System, 2015

Hispanic blacks (34.2\%; CI= 31.0-37.4); individuals with less than high school was 52.2\% (CI=46.7-57.8), and high school was $42.0 \%(\mathrm{CI}=38.7-45.4)$, which was higher when compared with post-high school $(33.4 \%$; $\mathrm{CI}=30.1-$ 36.6), college graduate $(32.5 \%$; $C I=29.3-35.6)$ (Table 1). These result showed that low level of education is associated low HBC screening The total percentage of those screened who had been told they had HBC was $38.7 \%$ $(\mathrm{CI}=36.9-40.6)$ which was lowered when compared to participants who reported no screening $(61.3 \%$; $\mathrm{CI}=59.4-$ 63.1) (Table 1).

According to Table 2, the percentage of participants who had their blood cholesterol checked within the last 5 years in male $(72.8 \%$; $\mathrm{CI}=69.8-75.7)$ was lowered when compared to female $(79.0 \%$; $\mathrm{CI}=76.8-81.3)$. Adults who did not check their blood cholesterol in the past five years in male $(2.5 \%$; $\mathrm{CI}=1.6-3.4)$ was slightly higher when compared to the female $(1.9 \% ; \mathrm{CI}=1.3-2.6)$ and the participants who never checked in male was $24.8 \%(\mathrm{CI}=21.8$ 27.7) and female (19.0\%; CI=16.8-21.2) (Table 2). The percentage of adults who had their blood cholesterol checked within the last 5 years was highest in 65 and above $(94.2 \%$; CI $=92.7-95.8)$, followed by $55-64$ years $(91.0 \%$; $\mathrm{CI}=88.8-93.1), 35-44(77.2 \% ; \mathrm{CI}=72.9-81.5), 25-34(59.2 \% ; \mathrm{CI}=53.9-64.6)$ and lowest in $18-24(40.2 \%$; $\mathrm{CI}=32.8-$ 47.6) (Table 2).

Among race/ethnicity, the prevalence of cholesterol screening was higher among non-Hispanic white (79.1\%; $\mathrm{CI}=79.6-81.4)$ when compared to the non-Hispanic black $(72.7 \%$; 69.4-75.9) (Table 2). The prevalence of blood cholesterol checked within the past 5 years in Mississippi among college graduate $(86.9 \%$; CI $=84.4-89.4)$ followed by some post-high school $(76.1 \%$; CI=72.8-79.4), high school $(73.2 \%$; $\mathrm{CI}=70.0-73.5)$ and participants with less than high school was the lowest with $69.1 \%$ and $\mathrm{CI}=63.7-74.5$ (Table 2). The percentage of participants who did not check their blood cholesterol within the last 5 years was 2.1\% (CI=1.2-3.0) among college graduate, some posthigh school was $2.7 \%(\mathrm{CI}=1.6-3.8)$ and $2.0 \%(\mathrm{CI}=1.1-2.9)$ in individual with less than high school (Table 2$)$. Among participants who never had their blood cholesterol checked within the last 5 years showed that college graduate was low (11.0\%; CI;8.7-13.4), followed by some post-high school $(21.2 \%$; CI=18.0-24.4), high school (24.8\%; CI $=21.5-28.0)$ and less than high school (29.2\%; CI; 23.8-34.6) (Table 2). The total percentage of those screened within the last 5 years $(76.0 \%$; CI $=74.2-77.9)$, those who did not check their blood cholesterol in the last 5 years was lowered $(2.2 \%$; $\mathrm{CI}=1.6-2.7)$ when compared to participant who never checked $(21.8 \%$; CI=20.0-23.6) (Table 2). 


\section{DISCUSSION}

The findings in this report indicated that the overall percentage of adults who had their blood cholesterol checked during the preceding 5 years was higher when compared to adults who did not check or never checked their blood cholesterol during the same period (Table 2). Moreover, the overall percentage of adults who checked and had high blood cholesterol was lowered when compared to the adults who did not check (Table 1). These results revealed that screening for high blood cholesterol was low among individuals aged 18-44 years and participants with low level of education.

Increase in cholesterol awareness can be achieved if there is continuous implementation of heart-disease and stroke-prevention programs by Center for Disease Control and Prevention which started in 1998 (CDC, 2005b). In addition, self-reported high blood cholesterol increased because of increased awareness of health problem associated with HBC (CDC, 2012). A report recently published using nationally representative data showed that from 1999-2000 and 2009-2010, the percentage of high total serum cholesterol ( $\geq 240 \mathrm{mg} / \mathrm{dL}$ ) among the U.S. population aged $\geq 20$ years with measured serum cholesterol levels decreased from $18.3 \%$ to $13.4 \%$ (Caroll et al., 2012). The lower percentage of adults ever screened and had HBC indicated a reduction in the prevalence of cholesterol screening of HBC in Mississippi. Cholesterol levels can be decreased through dietary changes such as decrease intake of saturated fats and dietary cholesterol, increased physical activity, and medication treatment (National Cholesterol Education Program, 2001). Although considerable progress has been made in decreasing cholesterol levels beginning in mid-1980s (Cleeman and Lenfant, 1998). National health objective and the overarching goal of Healthy People 2020, which is the elimination of health disparities can be achieved, if public health community and health-care sectors emphasizes on cholesterol screening of young adults (Cleeman and Lenfant, 1998).

The outcome from this report are based on two limitations (CDC, 2012). Firstly, BRFSS includes only the U.S. population that are noninstitutionalized and excluded individuals in the households without a telephone (CDC, 2012). Secondly, data from BRFSS were self-reported and no direct measurement were done with BRFSS, the high blood cholesterol reported cannot be verified and management of the cholesterol level cannot be evaluated (CDC, 2012).

\section{CONCLUSION}

High blood cholesterol is a major risk factor for heart disease and stroke (CDC, 2005a). The reduction of heart attack and stroke can be prevented by screening thereby leading to the early detection of high blood cholesterol (Grundy et al., 2004). To achieve the goal of screening of high blood cholesterol in Mississippi, public health experts, health educators and health-care providers should educate people on early screening of blood cholesterol, particularly young adults and individuals with low educational attainment (CDC, 2012). Educational message reinforcement and high level of public awareness are strategies of reducing the blood cholesterol (Cleeman and Lenfant, 1998). Dietary modification can also reduce blood cholesterol, increased exercise and medications (National Cholesterol Education Program, 2001). The objectives of Healthy People 2020 can be achieved in Mississippi, if there is increased public education on cholesterol screening (Cleeman and Lenfant, 1998). The public health experts in Mississippi should educate people on cholesterol screening of young adults, especially the nonHispanic blacks.

\section{REFERENCES}

American Heart Association. (2005). Heart disease and stroke statistics—2005 update. Dallas, TX: American Heart Association. Available at: http://www.americanheart.org

American Heart Association. (2006). Cholesterol Statistics. Available at: www.americanheart.org/presenter.jhtml?identifier=536 (Accessed 20 November 2006)

Aranmolate, R. (2017a). Comparison of abnormal cholesterol in children, adolescent \& adults in the United States, 2011-2014: Review. Eur J Environ Public Health, 1(1), 4. https://doi.org/10.20897/ejeph.201704

Aranmolate, R. (2017b). Prevalence of obesity among youths in Mississippi: United States, 1999-2015. International journal of adolescent medicine and health.

Aranmolate, R. (2018). Marijuana use among youths in Mississippi, United States. International journal of adolescent medicine and health. https://doi.org/10.1515/ijamh-2017-0195

Arnett, D. K., Jacobs, D. R., Luepker, R. V., et al. (2005). Twenty-year trends in serum cholesterol, hypercholesterolemia, and cholesterol medication use: The Minnesota Heart Survey, 1980-1982 to 2000-2002. Circulation, 112, 3884-3891. https://doi.org/10.1161/CIRCULATIONAHA.105.549857 
Benjamin, E. J., Blaha, M. J., Chiuve, S. E., Cushman, M., Das, S. R., Deo, R., et al. (2017). Heart disease and stroke statistics-2017 update: A report from the American Heart Association. Circulation, 135, e1-e458. https://doi.org/10.1161/CIR.0000000000000485

CDC. (2001). State-specific Trends in High Blood Cholesterol Awareness among Persons Screened---United States, 1991-1999. MMWR, 50(35), 754-758.

CDC. (2005a). Trends in Cholesterol Screening and Awareness of High Blood Cholesterol-United States, 19912003. $M M W R, 54(35), 865-870$.

CDC. (2005b). CDC State Heart Disease and Stroke Prevention Program. Atlanta, GA: US Department of Health and Human Services, CDC. Available at: http://www.cdc.gov/cvh/state_program/index.html

CDC. (2011). Vital signs: prevalence, treatment, and control of high levels of low-density lipoprotein cholesterol. United States, 1999-2002 and 2005-2008. MMWR, 60(4), 109-14.

CDC. (2012). Prevalence of Cholesterol Screening and High Blood Cholesterol among Adults-United States, 2005, 2007, 2009. MMWR, 61(35), 697-702.

Cleeman, J. I. and Lenfant, C. (1998). The National Cholesterol Education Program: progress and prospects. $J A M A, 280,2099-2104$. https://doi.org/10.1001/jama.280.24.2099

Ford, E. S., Mokdad, A. H., Giles, W. H. and Mensah, G. A. (2003). Serum total cholesterol concentrations and awareness, treatment, and control of hypercholesterolemia among U.S. adults: findings from the National Health and Nutrition Examination Survey, 1999 to 2000. Circulation, 107, 2185. https:// doi.org/10.1161/01.CIR.0000066320.27195.B4

Grundy, S. M., Cleeman, J. I., Merz, C., et al. (2004). Implications of recent clinical trials for the National Cholesterol Education Program Adult Treatment Panel III Guidelines. Circulation, 110, 227-239. https://doi.org/10.1161/01.CIR.0000133317.49796.0E

Havranek, E. P., Mujahid, M. S., Barr, D. A., et al. (2015). Social determinants of risk and outcomes for cardiovascular disease: a scientific statement from the American Heart Association. Circulation, 132, 873-898. https://doi.org/10.1161/CIR.0000000000000228

Klein, R. J. and Schoenborn, C. A. (2001). Age adjustment using the 2000 projected U.S. population. Healthy People 2010 Stat Notes, 20, 1-10.

Link, B. G. and Phelan, J. (1995). Social conditions as fundamental causes of disease. J Health Soc Behav, 36, 80-94. https://doi.org/10.2307/2626958

Mensah, G. A., Mokdad, A. H., Ford, E. S. et al. (2005). State of disparities in cardiovascular disease in the United States. Circulation, 111, 1233-1241. https:// doir.org/10.1161/01.CIR.0000158136.76824.04

Mercado, C., DeSimone, A. K., Odom, E., Gillespie, C., Ayala, C., and Loustalot, F. (2015). Prevalence of cholesterol treatment eligibility and medication use among adults-United States, 2005-2012. MMWR, 64(47), 1305-11. https://doi.org/10.15585/mmwr.mm6447a1

Mississippi Behavioral Risk Factor Surveillance System. (2008). Mississippi State Department of Health

Mozaffarian, D., Benjamin, E. J., Go, A. S., et al. (2016). Heart Disease and Stroke Statistics-2016 Update: A Report from the American Heart Association. Circulation, 133, e38-e360.

Murphy, S. L., Kochanek, K. D., Xu, J. Q. and Arias, E. (2015). Mortality in the United States, 2014. NCHS data brief, no 229. Hyattsville, MD: National Center for Health Statistics.

National Cholesterol Education Program. (2001). Executive summary of the third report of the National Cholesterol Education Program (NCEP) Expert Panel on Detection, Evaluation, and Treatment of High Blood Cholesterol in Adults (ATP III). JAMA, 285, 2486-2497. https://doi.org/10.1001/jama.285.19.2486

Nguyen, D. T., Kit, B. K. and Carroll, M. D. (2015). Abnormal Cholesterol among Children and Adolescents in the United States, 2011-2014. NCHS Data Brief, no 228. Hyattsville, MD: National Center for Health Statistics.

Pletcher, M. J., Lazar, L., Bibbins-Domingo, K., et al. (2009). Comparing impact and cost-effectiveness of primary prevention strategies for lipid-lowering (2009). Ann Intern Med, 150, 243-254. https://doi.org/10.7326/00034819-150-4-200902170-00005

Ritchey, M. D., Wall, H. K., Gillespie, C., George, M. G. and Jamal, A. (2014). Division for Heart Disease and Stroke Prevention, CDC. Million hearts: prevalence of leading cardiovascular disease risk factors--United States, 2005-2012. MMWR Morb Mortal Wkely Rep, 63, 462-467.

US Department of Health and Human Services. (2000). Healthy people 2010 (conference ed, 2 vols). Washington, DC: US Department of Health and Human Services.

Vanessa, S. (2014). Report on the Burden of Chronic Diseases in Mississippi (pp. 23-24), Mississippi State Department of Health.

Yoon, S. S., Fryar, C. D. and Carroll, M. D. (2015). Hypertension prevalence and control among adults: United States, 2011-2014. NCHS data brief, no 220. Hyattsville, MD: National Center for Health Statistics. 